\title{
Near-Native Sociolinguistic Competence in French: Evidence from Variable Future-Time Expression
}

\author{
Aarnes Gudmestad \\ Virginia Polytechnic Institute and State University \\ Amanda Edmonds \\ Université Paul-Valéry Montpellier 3 \\ Bryan Donaldson \\ University of California, Santa Cruz \\ Katie Carmichael \\ Virginia Polytechnic Institute and State University
}

\begin{abstract}
This study aims to advance the understanding of sociolinguistic competence among nearnative speakers and to further knowledge about the acquisition of variable structures. We conduct a quantitative analysis of variable future-time expression in informal conversations between near-native and native speakers of French. In addition to examining linguistic constraints that have been investigated in previous research, we build on prior work by introducing a new factor that enables us to consider the role that formality of the variants plays in the use of variable future-time expression. We conclude by comparing these new findings to those for the same dataset and other variable structures (namely, negation and interrogatives, Donaldson, 2016, 2017) and by advocating for more research that consists of multiple, complementary analyses of the same dataset.
\end{abstract}

\section{Résumé}

Les objectifs de cette étude sont (a) d'apporter de nouvelles données relatives à la compétence sociolinguistique parmi des locuteurs non natifs qui ont un niveau très avancé dans leur langue étrangère et (b) de contribuer à nos connaissances sur l'acquisition des structures variables. Nous proposons une analyse quantitative de l'expression du futur dans des conversations informelles entre un locuteur très avancé et un locuteur natif du français. Afin de comprendre ce cas de variation, nous faisons appel à des facteurs linguistiques qui ont été identifiés dans des recherches précédentes, et nous proposons un nouveau facteur qui nous permet d'étudier le rôle joué par la formalité des variantes dans l'expression du futur. Pour conclure, nous comparons les résultats de cette analyse aux recherches précédentes qui ont examiné d'autres structures variables dans le même corpus (notamment, la négation et les interrogatives, Donaldson, 2016, 2017) et nous soulignons l'intérêt et l'importance de faire de multiples analyses complémentaires d'un seul corpus. 


\section{Near-Native Sociolinguistic Competence in French: Evidence from Variable Future- Time Expression}

In the current study we aim to further knowledge about sociolinguistic competence among additional language users (see The Douglas Fir Group, 2016, for use of the term additional language). Sociolinguistic competence involves the ability to vary language according to a range of linguistic and extra-linguistic (namely, social) factors. Variationist approaches (Labov, 1972) have been used to examine this ability, with scholars in the field of second language acquisition (SLA) concentrating on how additional language learners acquire and use variable structures (i.e., linguistic phenomena that are not categorical for native speakers [NSs]; cf. Geeslin and Long, 2014). Although this research has examined learners at different proficiency levels, resulting in observations about the developmental trajectory with numerous variable structures, less is known about how near-native speakers ${ }^{1}$ (NNSs) use variable structures. In the current study, we address how NNSs use variable structures by reporting on a new empirical study of variable use of future-time expression in French. Our primary goals are to examine the linguistic and sociostylistic constraints that condition NNSs' use of future-time expression in French and to compare their variable use to that of NSs with whom the NNSs have close relationships. ${ }^{2}$ As a secondary goal we briefly compare our results on future-time expression to findings from previous investigations that have examined how the same group of NNSs uses other variable structures (Donaldson, 2016, 2017). In so doing, we argue for the importance of multiple, complementary investigations of a single group of participants for advancing knowledge of sociolinguistic competence.

\section{Background}

In what follows we present two areas of research that are particularly relevant for the current study, discussing additional language variationist research before offering a concise overview of future-time expression in French.

\section{Additional language variation}

Sociolinguistic variation occurs when two or more forms or variants are used to convey the same function or meaning and the use of these variants is conditioned by a range of linguistic and extra-linguistic factors. ${ }^{3}$ Such instances of variation have been the object of study in variationist sociolinguistics, the approach we adopt. Typically, a quantitative paradigm, variationist sociolinguistics not only documents the frequency with which each variant occurs, but also offers probabilistic models that identify the linguistic and extra-linguistic factors that predict the use of a given variant. These statistical models have enabled researchers to characterize language variation and change among NSs (Tagliamonte, 2012) and, subsequently, among non-native speakers (Geeslin \& Long, 2014).

Preston's (2000) psycholinguistic model for interlanguage variation provides a theoretical explanation for additional language acquisition of variation. Reflecting on how variable structures are affected by social context, linguistic context, and time, Preston suggests that each (sub)conscious choice among variants - such as elle va (she's going) 
versus elle va aller (she's going to go) versus elle ira (she will go) - is impacted by probabilistic rankings at three different levels. Level 1 refers to extra-linguistic factors, including, among others, gender of the learner (e.g., Mougeon, Nadasdi, \& Rehner, 2010) and interactional norms (e.g., Tarone, 2007), such as style and formality. Level 2 concerns the linguistic factors that impact variation (e.g., adverbial specification for future-time expression in French, Nadasdi, Mougeon, \& Rehner, 2003), and Level 3 addresses time and illustrates how the linguistic and social factors that govern variation change over time as learners move along the developmental trajectory (e.g., Tarone \& Liu, 1995). As pointed out by Tarone (2007), the probabilistic nature of Preston's (2000) model is consistent with other usage-based models in SLA (see Ellis, 2012) and allows the researcher to conceive of extra-linguistic and linguistic factors and time in a single, psycholinguistic model.

Although we examine both Level 1 and Level 2 constraints in the present investigation, we highlight here one Level 1 issue that we aim to address, namely, the formality or sociostylistic nature of variants, because it has received less attention than the well-studied linguistic factors. Following Richards and Schmidt (2010), stylistic variation refers to "differences in the speech or writing of a person or group of people according to the situation, the topic, the addressee(s), and the location. Stylistic variation can be observed in the use of different speech sounds, different words or expressions, or different sentence structures" (p. 567). Mougeon et al. (2010) describe a continuum of sociostylistic markedness for variants with five main categories: marked informal variants, mildly marked informal variants, neutral variants, formal variants, and hyper-formal variants (p. 910). In general, some of the distinguishing characteristics are that formal variants correspond to prescriptive language rules and are common in written or careful speech, whereas informal variants diverge from standard language rules and are typical of casual speech. Neutral variants are similar to formal variants in that they correspond to standard language rules but differ because they "are not sociostylistically marked ... [and] stand as a default alternative to other marked standard or non-standard variants" (p. 9-10). In their investigation, Mougeon et al. analyzed the use of numerous variable structures by a group of instructed, immersion learners of French in Canada and found differences in their use of variants according to the sociostylistic value of the variant. Specifically, they observed that immersion learners overused formal variants and underused informal ones. The learners produced some but not all neutral variants as well (p. 109). The conclusion that instructed learners tend to overuse formal variants when compared to NSs is supported by other studies (Regan, Howard, \& Lemée, 2009; van Compernolle, 2015), and van Compernolle has called this aspect of sociolinguistic competence "non-native pragmatic conservatism" (p. 60).

Less research, however, has examined the role that the formality of variants plays in the use of variable structures by non-native speakers who are not in an instructional setting. Thus, we aim to continue this line of inquiry by studying a near-native population living in the target language environment. Importantly, our participant group has already been investigated with respect to two other variable structures - interrogatives (Donaldson, 2016) and negation (Donaldson, 2017) - allowing us to consider findings from multiple variable structures and, consequently, advance the understanding of near-native sociolinguistic competence for this group of participants. Among other issues, both of these studies have examined the sociostylistic value of these variable structures' variants and whether the NNSs' use is targetlike. This research draws on informal conversation data 
from ten NNSs and ten NSs of Hexagonal French. Donaldson (2016) detailed the full range of interrogative forms that NNSs and NSs used and compared their communicative function and how they were used in sociostylistic terms. The results showed that the NNSs converged toward NS use, both in terms of repertoire and use of formal and informal variants. Donaldson (2017) also provided evidence of near-nativeness with variable negation. The preverbal negative particle $n e$ is frequently omitted in informal spoken French. The results revealed no statistical difference between the NNSs' and NSs' rates of $n e$ deletion, and the NNSs were sensitive to all of the sociostylistic factors (e.g., topic seriousness) and most of the linguistic factors (e.g., clause type) that conditioned NSs' use. It bears mentioning that for topic seriousness, a factor included in the present investigation (see Data coding and analysis for further details), both participant groups increased their retention of $n e$ (the formal variant) in serious topics. Together, these investigations offer evidence of near-nativeness with the variable use of two grammatical structures that form part of sociolinguistic competence in French. Furthermore, although instructed learners tend to exhibit pragmatic conservatism (van Compernolle, 2015) by using formal variants at a higher rate than NSs (e.g., Mougeon et al., 2010; Regan et al., 2009), Donaldson (2016) argued, on the basis of these results, that "this type of stylistic infelicity can be overcome at the near-native level" (p. 496). We seek to ascertain whether this participant group exhibits near-nativeness with another variable structure - future-time expression.

\section{Future-time expression in French}

Future-time expression refers to verb forms that express a temporal reference posterior to the moment of speaking. The inflectional future (IF), periphrastic future (PF), and futurate present are the forms most often included in descriptions of future-time expression in French. The following are examples from the current dataset:

\begin{tabular}{|c|c|}
\hline IF: & $\begin{array}{l}\text {... quelque chose qui terminera ce cycle-là (NNS 10) } \\
\text {... something that will finish the cycle' }\end{array}$ \\
\hline PF: & tu sais pas à quelle heure tu vas terminer tout? (NS 3) \\
\hline Futurate present: & $\begin{array}{l}\text { je termine à dix heures et demie (NS 5) } \\
\text { 'I finish at 10:30' }\end{array}$ \\
\hline
\end{tabular}

Future-time expression in French constitutes an example of morphosyntactic variation conditioned by various linguistic and extra-linguistic factors (Poplack \& Turpin, 1999). In this section we offer a brief overview of sociolinguistic research on future-time expression in French among NSs, followed by a discussion of studies on non-native speakers.

NS sociolinguistic research. Sociolinguistic research on future-time expression in French has centered on Canadian varieties (e.g., Comeau, 2011; Poplack \& Dion, 2009; Wagner \& Sankoff, 2011) and to a lesser extent Hexagonal (i.e., French in mainland France; e.g., Gudmestad, Edmonds, Donaldson, \& Carmichael, 2018; Roberts, 2012; Villeneuve \& Comeau, 2016) and Martinican (Roberts, 2016) varieties. We highlight the independent variables that have been studied in previous research and then focus on the 
evidence of the importance of formality in the use of this variable. We conclude the section with a detailed presentation of the research examining Hexagonal French, the variety represented in our data.

Numerous factors have been examined in variationist studies on future-time expression in different varieties of French. Extra-linguistic factors include education level, age, and gender, and well-studied linguistic factors include temporal distance,

(un)certainty, adverbial specification, sentential polarity, and grammatical person. These various linguistic factors have been taken both from descriptions of future-time expression in grammars and from the literature on future-time expression (see Poplack \& Dion, 2009). Temporal distance refers to the distance between the time of speaking and future-time event. (Un)certainty deals with how certain the speaker is that the future-event will occur. Adverbial specification identifies whether temporal adverbials accompany future-time verbs. Sentential polarity distinguishes negated from affirmative sentences, and grammatical person reflects the person and number of the subject. We continue the exploration of many of these factors in the current study.

Concerning the construct of sociostylistic variation and formality, two empirical observations have provided evidence that IF is the formal variant in variable future-time expression. First, by investigating the linguistic factor of grammatical person of the subject, research has shown a connection between the IF and the formal second-person pronoun vous (e.g., Poplack \& Turpin, 1999, for Canadian French, and Roberts, 2012, for Hexagonal French). Second, Blondeau and Labeau (2016) analyzed formal, prepared language used in oral televised weather forecasts and found that both French and Québécois weathercasters used the IF more often than the PF, a finding that contrasts with results from examinations of interview data for these varieties, in which the PF was the most frequent form. This difference across genres suggests an extra-linguistic, sociostylistic distinction between the PF and IF, with the IF being the formal variant. Whereas the IF has been associated with formality, the futurate present and the PF have been categorized as neutral variants (e.g., Mougeon et al., 2010).

To conclude our discussion of future-time expression in NS French, we present two variationist studies on future-time expression in Hexagonal French. ${ }^{4}$ Roberts (2012) examined oral interviews collected in the 1980s in the north and south of France. He found that, as a group, these NSs used the PF more often than the IF and that sentential polarity was the sole predictive factor. These NSs favoured the PF in affirmative contexts and the IF in negative contexts. Villeneuve and Comeau (2016) investigated NSs from Vimeu, in northern France. Their analysis of interview data indicated that, like in Roberts (2012), participants used the PF more frequently than the IF. The factors predicting use, however, differed from Roberts' study. The linguistic factor that conditioned future-time expression was temporal distance, where proximal contexts favoured the PF and distal contexts favoured the IF. Education level was the only social factor that impacted use. Participants without a high school diploma favoured the PF, whereas those who had completed high school favoured the IF. The differences in results between these two studies not only demonstrate that additional research is needed in order to better understand variable futuretime expression among NSs of Hexagonal French but also underscore the need, in additional language research, to identify a NS comparative group that is appropriate for the additional language speakers under investigation. 
SLA research. Turning to SLA research, analyses of future-time expression in French come from several types of data (e.g., interviews, written contextualized tasks) and participant groups, though previous studies have generally focused on instructed learners in various learning contexts (e.g., Ayoun, 2014; Howard, 2012a; Moses, 2002). Four insights emerge from this body of work. ${ }^{5}$ First, with regard to frequency of use of verb forms in future-time contexts, classroom learners use the IF at higher rates than the PF (e.g., Howard, 2012a, 2012b; Moses, 2002), possibly because of the tendency to overuse formal variants. Immersion experiences, however, lead to lower rates of the formal variant and higher rates of the neutral variant PF (e.g., Howard, 2012b; Mougeon et al., 2010, see Regan et al., 2009, for an exception). Second, several previous investigations have examined many of the same linguistic factors that have been shown to predict NS use and found differing results across studies (Blondeau, Dion, \& Ziliak Michel, 2014; Edmonds \& Gudmestad, 2015; Gudmestad \& Edmonds, 2016; Howard, 2012b, Mougeon et al., 2010; Nadasdi et al., 2003; Regan et al., 2009). For instance, concerning adverbial specification, the presence of a temporal adverbial favoured the occurrence of the futurate present among Canadian immersion students (Mougeon et al., 2010; Nadasdi et al., 2003), Irish studyabroad learners (Regan et al., 2009), adult Anglo-Montrealers (Blondeau et al., 2014), Level 3 study-abroad learners (Edmonds \& Gudmestad, 2015), and study-abroad learners with high proficiency (Gudmestad \& Edmonds, 2016). However, this effect was not found for all study-abroad and foreign-language classroom learners reported on by Edmonds and Gudmestad (2015) and Gudmestad and Edmonds (2016). Third, with the exception of Anglo-Montrealers (Blondeau et al., 2014), no study has shown evidence of learners becoming fully targetlike with future-time expression. Finally, two investigations have addressed sociostylistic variation, specifically pertaining to formality. Neither immersion learners (Nadasdi et al., 2003), nor university learners who had spent an academic year in France (Regan et al., 2009) favoured the use of the IF with the subject pronoun vous, as has been reported for certain groups of NSs. Regan et al. (2009) did, however, find that style

formality constrained use. The researchers differentiated between formal and informal style based on the interview topic and found that the participants favoured the IF with formal topics and the PF and futurate present with informal topics. This observation suggests that non-native speakers can develop sensitivity to sociostylistic constraints of variable futuretime expression in French. We aim to build on this existing research by investigating how another participant population - NNSs - uses variable future-time expression.

\section{The Current Study}

Our two research questions are formulated with the objectives of contributing new knowledge on variable future-time expression among NNSs:

1. With what frequency do NNSs of Hexagonal French use the IF, PF, and present indicative (PI) to express future-time expression in informal, unstructured conversation?

2. Which linguistic and sociostylistic factors predict NNSs' use of the IF, PF and PI in informal, unstructured conversation? 


\section{Method}

\section{Dataset and participants}

This dataset consists of 10 unguided conversations between a NNS and a NS of French. The conversations, which lasted between 45 and 58 minutes, were recorded in an informal setting without the presence of a researcher. The participants spoke about any topic(s) of their choosing. The conversation partners knew each other well (e.g., spouses, friends), which aided in eliciting informal speech (cf. Donaldson, 2017). The data were collected mostly in southwest France, though one conversation was collected in Paris. We argue that this NS group is particularly well-suited as a comparison group because the NNSs have close relationships with the NSs. The dataset consists of 77,300 words (excluding non-lexical backchannels, hesitations, etc.) and is balanced quantitatively between NS and NNS production (5,300 and 5,600 finite clauses, respectively). Donaldson (2016, 2017, inter alia) demonstrates that that there is no evidence that either participant group is accommodating to the other.

The ten NNSs, whose first language was English, ranged in age from 26 to 70 years $(M=44.2)$. Eight were women and two were men. All were university educated. They began studying French between the age of 10 and 21 years $(M=13)$ and had been living in France for an average of 18 years and seven months (range in years;months: 4;3-47;3). ${ }^{6}$ All NNSs interacted daily with NSs. The ten NSs of Hexagonal French ranged in age from 31 to 65 years $(M=49.5)$. Seven were women and three were men. ${ }^{7}$ All had earned the French baccalauréat (roughly equivalent to a secondary school diploma), and nine of the ten were university educated. They were dominant in French but had varying degrees of experience with other additional languages. In general, the NSs were close in age and education level to their NNS interlocutor. Each participant completed a replication of Birdsong's (1992) grammaticality judgment task, which was used to assess near-nativeness. The results revealed that the NNSs had achieved near-native grammatical knowledge of French. While further refinements to measuring near-nativeness are necessary, we note that prior investigations on these participants have shown them to have nativelike behaviour on a range of linguistic phenomena (Donaldson, 2016, 2017, inter alia).

All datasets present strengths and limitations. One advantage of this dataset is that it allows us to contribute knowledge about near-native sociolinguistic competence (cf. Geeslin \& Long, 2014). It also enables us to extend additional language variationist research on future-time expression to another type of data - informal conversations. Finally, we feel confident that the sample is representative of the speakers' informal spoken French, because their interlocutor is someone they know well. However, given the restricted number of total speakers and the design of the corpus, certain extralinguistic characteristics, including speaker age, gender, and regional provenance, cannot be investigated. Although these factors may merit additional attention, existing research on Hexagonal French has found neither age nor gender to be conditioning factors for futuretime expression (Roberts, 2012; Villeneuve \& Comeau, 2016). With respect to potential regional variation, only Villeneuve and Comeau have conducted an analysis of future-time expression in France that has focused on a single regional variety. Whereas it remains to be seen whether their findings hold for Hexagonal French more generally, we note that extensive work by Armstrong and Pooley (2010) shows evidence of leveling of regional 
differences in Hexagonal French. Finally, we recognize that time spent abroad may impact use for the NNSs. We leave these issues to future research.

\section{Data coding and analysis}

After the third author and a NS of French had transcribed the conversations, we coded the transcripts for future-time contexts. We operationalized a future-time context as any conjugated verb with a temporal reference subsequent to the moment of speaking (cf. Blondeau et al., 2014). We used contextual information, such as shared knowledge, subject matter, and temporal expressions to establish futurity. This definition means that the presence of the PF or IF did not necessarily constitute a future-time context because these forms can express other functions (e.g., PF can be used to talk about habitual actions not set to occur in the future, Poplack \& Turpin, 1999). To establish reliability in the coding, two authors coded every transcript independently and then compared their coding. Any disagreements were resolved with the help of a third author.

After identifying future-time contexts, we coded each case for the dependent variable and five independent variables. The verb form used in a future-time context was the dependent variable. We focused on three of the most frequent forms identified in Edmonds, Gudmestad, and Donaldson (2017): PF, PI, and IF. The IF warranted special coding considerations because of homophony in the verb system in Hexagonal French. First, the first-person singular forms of the conditional (je verrais [I would see]) and the IF (je verrai [I will see]) tend to be homophonous in informal Hexagonal speech. These forms maintain a spelling difference in the final morpheme, which reflects the fact that in the past there was a phonetic difference. Although the phonetic distinction can still occur in contemporary formal speech (e.g., Armstrong \& Pooley, 2010; Hansen, 2016), this presentday homophony in informal speech means that we could not empirically distinguish firstperson singular IF and conditional forms in our oral data. The analysis of the IF thus excludes first-person singular forms. Another coding decision pertained to present-tense forms that conveyed futurity. In French most present forms do not contain overt morphology that signifies its verbal mood. In other words, although some forms have morphology that marks them as an indicative or subjunctive form (e.g., $t u$ viens INDIC $_{\text {versus }}$ tu viennes $s_{\text {SUBJC }}$ [you come]), most present forms are homophonous in the indicative and subjunctive (e.g., j'étudie [I study] in both moods). In addition to this homophony, there is also evidence of variation in the use of verbal moods in subordinate clauses (e.g., Gudmestad \& Edmonds, 2015; Poplack, Lealess, \& Dion, 2013). Because of these two characteristics of present forms, which result in some ambiguity in the mood of many present forms, we distinguished among three forms in dependent clauses: PI, present subjunctive, and present ambiguous. Given that there is no evidence of mood variation in independent clauses, we differentiated between two forms: PI and present ambiguous. Thus, in the current study, our analysis includes PI forms only, whereas in previous research, it appears that the futurate present also consisted of present ambiguous forms (see Gudmestad et al., 2018, for a more detailed discussion of coding decisions).

In terms of independent variables, we investigated two levels of the psycholinguistic model for interlanguage variation (Preston, 2000), namely Level 2 (four linguistic factors) and Level 1 (one sociostylistic factor). Because we are examining NNSs at one point in time, we do not consider Level 3 (time) of the model. The independent 
linguistic factors were sentential polarity, (un)certainty, temporal distance, and lexical temporal indicator (LTI). ${ }^{8}$ For sentential polarity, we coded for the presence or absence of a verbal negator (negative and positive sentences, respectively). (Un)certainty reflected whether the future-time context was accompanied by an overt expression of (un)certainty in the same clause as the verb or the immediately previous clause. The categories were: the presence of a certainty marker (e.g., certainement [certainly]), the presence of an uncertainty marker (e.g., je sais pas [I don't know]), and the absence of a marker. ${ }^{9}$ With temporal distance we identified the distance between the future event and the moment of speaking. The five categories were: greater than one month, less than one month, less than one week, today, and ambiguous. The final linguistic factor, LTI, investigated temporal markers signifying futurity that occurred in the same clause as its corresponding verb form. ${ }^{10}$ This variable consisted of three categories: the presence of a time-non-specific LTI (e.g., plus tard [later]), the presence of a time-specific LTI (e.g., aujourd'hui [today]), and the absence of a LTI. ${ }^{11}$ The sociostylistic factor was topic seriousness. Although this variable has not, to our knowledge, been investigated with respect to future-time expression in French, we examined it because we felt that it was the most appropriate way to explore formality in the current dataset. This issue has most often been investigated in future-timereference research with respect to the verb form favoured with the formal vous, but this pronoun is rare in our dataset. We considered the concept of style, as operationalized by Regan et al. (2009) but chose instead the concept of topic seriousness, which was explored in Donaldson's (2017) study of negation in these data. This decision has the important advantage of allowing us to compare findings for the same factor across studies involving the same participant group. More specifically, serious topics (within an otherwise informal register) have been linked with greater use of the formal variant of variable negation in French (e.g., Sankoff \& Vincent, 1977), a finding that was also borne out in Donaldson (2017). Such (usually temporary) stylistic shifts within the context of a given register are labeled "micro-style variation" by Armstrong (2002, p. 171). As the IF has been described as a formal future-time verb form (e.g., Mougeon et al., 2010), topic seriousness may influence its use. Following previous literature (e.g., Fonseca-Greber, 2007; Poplack \& StAmand, 2007), we coded as serious topics discussions of religion, sermons, moralizing, education, the discipline of children, meetings, one's profession, and the legal system. All other topics were coded as non-serious. A final extra-linguistic factor was participant group; we conducted separate analyses for the NNSs and NSs.

We began the analysis with a cross-tabulation to determine the frequency of use of the PF, PI, and IF in future-time contexts. Next, using the statistical software R, we generated a multinomial logistic regression to identify the independent linguistic variables that conditioned the use of the verb forms under investigation. ${ }^{12}$ This regression analyzes the PF, PI, and IF in a single model, and, to our knowledge, the current study is the first to apply this type of statistical analysis to production data for variable future-time expression in additional language French. It compares one variant of the dependent variable (the reference point) with the other two variants separately. In the current study the IF is the reference point and this form is compared to the PF and the PI. We generated separate multinomial regression models for the NS and NNS data, testing predictors for three futuretime expression forms: IF, PF, and PI. The best model of the data was selected through a "step-up" procedure in $\mathrm{R}$ in which predictors were added to a bare model one at a time. Then a model comparison was completed through an ANOVA, resulting in the final model 
that includes only the predictors that significantly improved the model's ability to predict the variation observed. The predictors reveal the linguistic and sociostylistic constraints on the use of the future-time verb forms under investigation and the ways in which they impact use (i.e., the direction of the effects). To make assessments about targetlike use, we compare the NS and NNS groups' frequency of use of the three verb forms and the factors that condition this use.

\section{Results}

The NNSs produced 345 future-time contexts and the NSs produced 308 futuretime contexts. We begin with the frequency of use of the three verb forms under investigation (Table 1). Descriptively, the largest difference between the two participant groups is with the IF. The NSs used the IF more frequently than the NNSs $(23.1 \%$ versus $14.5 \%$, respectively). As concerns the hierarchy of use, the NNSs used the PF most often, followed by the PI, and, lastly, the IF. The NSs paralleled this use somewhat, though their use was not dramatically different between the PI and IF.

Table 1

\begin{tabular}{lllll} 
Frequency of verb forms \\
\cline { 2 - 5 } Verb form & $\#$ & NNSs & NSs & \# \\
\cline { 2 - 5 } & $\#$ & 58.0 & 159 & 51.6 \\
PF & 200 & 27.5 & 78 & 25.3 \\
PI & 95 & 14.5 & 71 & 23.1 \\
IF & 50 & 100 & 308 & 100 \\
\hline Total & 345 & & & \\
\hline
\end{tabular}

For the second phase of the analysis, we generated a multinomial regression for each participant group to identify the linguistic and sociostylistic factors that influenced use of the PF, IF, and PI in future-time contexts. As previously mentioned, this statistical test compares a reference point of the dependent variable (IF) against the other two forms independently (PF and PI). Just as with the dependent variable, the test considers a reference point of an independent variable against the other categories of that variable. The reference points in the current study are the categories of today (temporal distance), none (LTI), absence of a negator (polarity), and non-serious (seriousness of topic). For example, for LTI, instances of future-time reference with no adverbial specification (the reference point) were compared, separately, to cases where a time-specific LTI was present and to cases involving a time-non-specific LTI. Although we began the analysis with the inclusion of a fourth linguistic factor, (un)certainty, we were not able to include this variable in the regression model due to the low occurrence of (un)certainty markers. ${ }^{13}$ The details of the regression models are available in Tables $2,3,4$, and 5 . In these tables a negative coefficient means that the likelihood of using the PI or the PF is lower than the IF with a given factor. Similarly, a positive coefficient means that the likelihood of using the PI or $\mathrm{PF}$ is higher than the IF with a given factor. The $p$ value shows whether the presence of that predictor significantly predicts the future-time verb form (values less than $<0.05$ are statistically significant). 
Tables 2 and 3 illustrate the results of a single multinomial regression model for the NNSs. The NNS model demonstrates that LTI and topic seriousness, but not temporal distance or polarity, predicted verb-form use in future-time contexts (see the Appendix for the distribution of the verb forms according to temporal distance and polarity). Regarding LTI, the NNSs were more likely to use the PI than the IF in the presence of a time-specific LTI compared to the absence of a LTI. No significant effects for LTI were observed for the PF-IF comparison. Moreover, the NNSs were less likely to use the PI and PF compared to the IF when the discourse topic was serious. In other words, serious topics significantly predicted the use of the IF.

Table 2

Multinomial regression model for NNSs: PF vs IF

\begin{tabular}{lccc}
\hline Factor & Coefficient & Standard error & $p$ value \\
\hline $\begin{array}{l}\text { LTI } \\
\text { (reference point: none) }\end{array}$ & & & \\
$\quad$ time-non-specific & -0.3514 & 0.5161 & 0.4959 \\
$\quad$ time-specific & 0.2762 & 0.5331 & 0.6044 \\
& & & \\
SERIOUS & & & \\
(reference point: non-serious) & & $\mathbf{0 . 3 8 5 3}$ & $\mathbf{0 . 0 0 5 6}$ \\
$\quad$ yes & $\mathbf{- 1 . 0 6 6 8}$ & &
\end{tabular}

Note. Significant effects are in bold.

Table 3

Multinomial Regression Model for NNSs: PI vs IF

\begin{tabular}{lccc}
\hline Factor & Coefficient & Standard error & $p$ value \\
\hline $\begin{array}{l}\text { LTI } \\
\text { (reference point: none) }\end{array}$ & & & \\
$\quad$ time-non-specific & -0.1344 & 0.6108 & 0.8258 \\
$\quad$ time-specific & $\mathbf{1 . 8 0 7 4}$ & $\mathbf{0 . 5 4 3 7}$ & $\mathbf{0 . 0 0 0 9}$ \\
& & & \\
SERIOUS & & & \\
(reference point: non-serious) & & & $\mathbf{0 . 0 0 0 2}$ \\
$\quad$ yes & $\mathbf{- 2 . 1 3 9 5}$ & $\mathbf{0 . 5 8 2 8}$ & \\
\hline
\end{tabular}

Note. Significant effects are in bold.

Turning to the NSs, the regression model revealed that all four factors worked together to predict the use of the PF, IF, and PI in future-time contexts. The PF-IF comparison (Table 4) shows that these NSs were less likely to use the PF than the IF when an event was less than a week away compared to today. There was no significant difference between these forms and the other categories of temporal distance. The NSs also exhibited lower odds of using the PF over the IF when a time-non-specific LTI was present compared to absent, but there was no significant difference with time-specific LTIs. In terms of polarity, they were less likely to use the PF than the IF when a verbal negator was 
present (i.e., negative). There was no significant difference between the IF and PF with regard to seriousness of topic. Concerning the PI-IF comparison (Table 5), these NSs showed higher odds of using the PI versus the IF when a time-specific LTI was present compared to absent. There was no significant difference between time-non-specific LTIs and the absence of a LTI. For topic seriousness, they were less likely to use the PI compared to the IF when the topic was serious. The model did not reveal significant differences between these two verb forms with regard to temporal distance or polarity.

Table 4

Multinomial regression model for NSs: PF vs IF

\begin{tabular}{|c|c|c|c|}
\hline Factor & Coefficient & Standard error & $p$ value \\
\hline \multicolumn{4}{|l|}{$\begin{array}{l}\text { TEMPORAL DISTANCE } \\
\text { (reference point: today) }\end{array}$} \\
\hline less than a week & -1.3543 & 0.6716 & 0.0438 \\
\hline less than a month & -0.9975 & 0.8440 & 0.2373 \\
\hline greater than a month & -0.0789 & 0.6735 & 0.9068 \\
\hline ambiguous & -0.1950 & 0.6117 & 0.9068 \\
\hline \multicolumn{4}{|l|}{$\begin{array}{l}\text { LTI } \\
\text { (reference point: none) }\end{array}$} \\
\hline time-non-specific & -1.8254 & 0.6486 & 0.0049 \\
\hline time-specific & 0.0876 & 0.4767 & 0.8541 \\
\hline \multicolumn{4}{|c|}{$\begin{array}{l}\text { POLARITY } \\
\text { (reference point: positive) }\end{array}$} \\
\hline negative & -0.8681 & 0.4042 & 0.0317 \\
\hline \multicolumn{4}{|c|}{$\begin{array}{l}\text { SERIOUS } \\
\text { (reference point: non-serious) }\end{array}$} \\
\hline yes & -0.5487 & 0.4224 & 0.1940 \\
\hline
\end{tabular}

Note. Significant effects are in bold. 
Table 5

Multinomial Regression Model for NSs: PI vs IF

\begin{tabular}{lccc}
\hline Factor & Coefficient & Standard error & $p$ value \\
\hline $\begin{array}{l}\text { TEMPORAL DISTANCE } \\
\text { (reference point: today) }\end{array}$ & & & \\
$\quad$ less than a week & -0.6664 & 0.7604 & 0.3808 \\
$\quad$ less than a month & 0.4262 & 0.8664 & 0.6228 \\
$\quad$ greater than a month & -0.4832 & 0.8020 & 0.5468 \\
$\quad$ ambiguous & -0.3408 & 0.7297 & 0.6405 \\
& & & \\
LTI & & & 0.7697 \\
(reference point: none) & & & \\
$\quad$ time-non-specific & & & \\
$\quad$ time-specific & 0.1658 & $\mathbf{0 . 4 8 5 4}$ & \\
$\begin{array}{l}\text { POLARITY } \\
\text { (reference point: positive) }\end{array}$ & $\mathbf{1 . 7 8 7 1}$ & & 0.0810 \\
$\quad$ negative & & & \\
$\begin{array}{l}\text { SERIOUS } \\
\text { (reference point: non-serious) }\end{array}$ & & & \\
$\quad$ yes & -1.0143 & & $\mathbf{0 . 0 1 3 5}$ \\
\hline
\end{tabular}

Note. Significant effects are in bold.

When we compare the linguistic factors in the NNS and NS models, we see that temporal distance and polarity were influential factors for the NSs, but these factors were not significant for the NNSs. However, LTI was a significant constraint for both groups. Although the NNSs did not exhibit the targetlike significant effect for time-non-specific LTIs in the PF-IF comparison, they were similar to the NSs with the time-specific LTIs and PI-IF comparison. In terms of the sociostylistic factor of topic seriousness, the NSs were more likely to use the IF than the PI with serious topics but showed no differences with this factor for the PF-IF comparison. For the NNSs, however, this effect was significant for the PI-IF and PF-IF comparisons. Thus, they were nativelike insofar as serious topics significantly predicted the use of the IF compared to the PI, although their sensitivity to seriousness was stronger than that of the NSs, as it also constrained the PF-IF comparison. In general, this analysis revealed a similarity in the hierarchy of verb-form frequency and differences in the contexts of use of these forms, which appear to demonstrate that this group of NNSs is not entirely nativelike in their use of the IF, PF, and PI in contexts of future-time expression.

\section{Discussion}

In what follows, we offer answers to the research questions based on the present investigation's findings. We also briefly compare the results on future-time expression to 
those on interrogatives and negation (Donaldson, 2016, 2017) in order to better understand the use of variable structures by the same group of NNSs. Then, we turn to a discussion of the current study's overarching contributions. Specifically, we elaborate on the implications of multiple, complementary investigations of a single dataset for advancing knowledge of SLA in general and sociolinguistic competence in particular.

\section{Main findings}

The first research question concerned the NNSs' frequency of use of the PF, PI, and IF in future-time contexts and how these rates of use compared to those of the NS interlocutors. The NNSs used the PF most often, followed by the PI, and, lastly, the IF in informal conversations. This general frequency pattern is similar to some study-abroad learners (Howard, 2012b) and to immersion learners (Mougeon et al., 2010; Nadasdi et al., 2003), who used the PF most often in a semi-guided interview. Furthermore, the results demonstrated that, for the most part, the NNSs paralleled the NSs' hierarchy of use. One final observation concerning frequency pertains to the IF, which has been cited as the formal verb form for future-time expression (e.g., Mougeon et al., 2010): the NNSs used this form less often than the NSs. Whereas there is ample evidence in the literature showing that (especially classroom) learners tend to overuse the formal variant, the pattern in the current dataset suggests that these NNSs do not exhibit pragmatic conservatism (van Compernolle, 2015) with future-time expression. This finding is consistent with results found for interrogative forms and negation with the same group of participants (Donaldson, 2016,2017 ) and may be related to the fact that they have many "active commitments" (Mougeon \& Rehner, 2015) to the target language and their community, meaning they are well integrated into the community and do not consider themselves to be outsiders.

The second research question investigated which factors predicted NNSs' use of the IF, PF, and PI in future-time contexts and how these predictive factors compared to those of the NSs. We found that the linguistic factor of LTI and the sociostylistic factor of topic seriousness were included in the NNS model. The NNSs were less likely to use the IF, versus the PI, when a time-specific LTI was present. Additionally, they were more likely to use the IF, compared to the PF or PI, when the discourse topic was serious. These results differ from previous variationist work on future-time expression in additional language French among study-abroad learners in which the occurrence of future-time verb forms was constrained by a range of linguistic factors such as temporal distance, LTI, and polarity (Gudmestad \& Edmonds, 2016; Regan et al., 2009), but they are similar to Nadasdi et al. (2003), who found that adverbial specification (i.e., LTI) was the sole linguistic predictor for immersion learners. Differences among these investigations in terms of data types and French proficiency, however, make it difficult to draw conclusions about these divergent findings. In contrast to the NNSs, the NSs exhibited significant effects for the three independent linguistic variables included in the multinomial regression: temporal distance, polarity, and LTI. Topic seriousness was included in the regression model but, unlike the NNSs, a significant effect was found for the PI-IF comparison only. The NSs' preference for the IF compared to the PI with serious topics corroborates the claim that the IF is a formal variant (cf. Mougeon et al., 2010; Roberts, 2012).

Considering both predictive models together, the findings indicated that, despite having converged toward a NS target for negation and interrogatives (as discussed in 
Additional language variation), these NNSs exhibited some differences from the NS group with variable future-time expression, insofar as two linguistic factors that significantly influenced NS use were not included in the NNS model. Moreover, we found that the NNSs were more constrained by topic seriousness than the NSs because this factor conditioned their use of not only the PI-IF comparison, but also the PF-IF distinction. The results for this factor suggest that the NNSs have made a stronger association between the IF and formality than the NSs. Perhaps worth noting as well is that the findings for the NNS regression model appear to indicate that these NNSs are sensitive to style and characteristics of discourse, more so than linguistic factors - at least with regard to the constraints under investigation. This observation stems from the results that two of the linguistic factors under investigation (polarity and temporal distance) did not impact their use of future-time verb forms, that LTI was significant for the PI-IF comparison only, and that topic serious constrained use for both comparisons (i.e., all verb forms under investigation). Whereas research has shown that stylistic variation is an acquisitional challenge for non-native speakers (e.g., Sax, 2003), this group of NNSs is sensitive to a subtle indicator of style - topic seriousness - in their use of variable future-time expression.

\section{Overarching contributions to SLA}

Rich, multifaceted analyses of a single group of non-native speakers have become more feasible, thanks in part to researchers who have made additional language corpora publicly available, allowing for many different researchers to work on the same dataset (e.g., Granger, 2009; MacWhinney, 2000; Mitchell, Tracy-Ventura, \& McManus, 2017). This trend stands to improve the generalizability of findings, which can be difficult to achieve when scholars are faced with making comparisons across investigations with diverse research designs. We agree with the need for a multifaceted approach to SLA research and argue that it is essential for furthering the understanding of additional languages in general and of near-native sociolinguistic competence more specifically. In the case of the current dataset, these informal, unguided conversations have been used to investigate multiple variable structures. We are thus able to articulate our new findings on future-time expression with the existing research on these speakers, resulting in a more nuanced characterization of near-native sociolinguistic competence in informal French than would otherwise be possible. Specifically, although these NNSs' use of interrogative forms and negation were largely targetlike (Donaldson, 2016, 2017), they exhibited various patterns in their use of the PF, IF, and PI in future-time contexts that differed from the patterns of the NS group. Thus, this comparison of findings from different linguistic phenomena and the same participant population enables us to see that these NNSs have exhibited differing outcomes for these variable structures, and, consequently, leads to a follow-up question: why have these NNSs converged with NSs to a larger degree with interrogatives and negation than future-time expression? While a complete answer to this question is beyond the scope of the current investigation, we offer a preliminary reflection on the question of varying outcomes of variable structures that emerged from our comparison of the current study, Donaldson (2016), and Donaldson (2017). Ultimately, our hope is to encourage more analyses of a single participant pool that aim to contribute to the understanding of sociolinguistic competence. ${ }^{14}$ 
We focus our reflection on differing outcomes of variable structures on the formality of the variants. As mentioned in the Background section, sociolinguistic research has classified different variants on the basis of their level of formality (e.g., Mougeon et al., 2010) and variationist research has suggested that this feature plays a role in additional language development. In particular, instructed learners tend to use formal variants at higher rates than informal or neutral variants (e.g., Howard, 2012a; Kanwit, Geeslin, \& Fafulas, 2015; Mougeon et al., 2010), showing evidence of non-native pragmatic conservatism (van Compernolle, 2015). Moreover, Kanwit et al. (2015), in their study of three variable morphosyntactic structures among study-abroad learners in Mexico and Spain, hypothesized that the level of consciousness with regard to whether variants carry stigma or prestige among NSs likely impacts the input learners receive, which in turn could influence acquisition. Although what is meant by "level of consciousness" remains to be operationalized clearly, this observation seems to suggest in part that the salience of a variant's formality may impact additional language development (see Gass, Spinner, \& Behney, 2018, for recent research on salience, and Billieaz \& Buson, 2013, for a discussion of perceived formality of different variable features in Hexagonal French).

Concerning the variable structures at hand, each has a formal variant: ne retention (negation), interrogative inversion (interrogative forms), and the IF (future-time expression) (Armstrong, 2001; Mougeon et al., 2010). Despite this similarity, research on the NNSs under investigation reveals differing outcomes with regard to targetlike use for these forms and the variable structures as a whole. It will be recalled that these NNSs appeared to be more targetlike with negation and interrogative forms than the future-time expression. One possible hypothesis for the varying outcomes with these three variable structures may have to do with the relative degree of formality of the variants. For instance, although it may be the case that many variable structures have a formal variant, the level of formality expressed when a speaker opts for the IF may be relatively lower than that of ne retention and interrogative inversion, which may communicate a comparatively high level of formality (see Mougeon et al., who rank variants along a continuum in terms of formality, with five different levels of (in)formality). If true, this observation could essentially mean that the stakes are higher for NNSs who have not mastered a variable structure whose variants diverge notably in terms of formality (such as negation and interrogatives) than for a variable structure whose variants show less divergence (i.e., future-time expression). In other words, consequences associated with non-nativelike use of variable structures may vary from one structure to the next. This may be because the use of a less formal variant (such as the PF or PI) in formal contexts may be less stigmatized than the use of informal variants for the other two variable structures (cf. Kanwit et al., 2015). Another possibility is that these three formal variants may be similar in their level of formality, but that IF is a less salient indicator of formality than $n e$ retention and interrogative inversion, so NNSs could be less aware of this sociostylistic feature (see Billiez \& Buson, 2013). It may also be, however, that the degree to which NNSs feel integrated into the target community and the extent to which they share the values of formality present in the community (cf. Mougeon \& Rehner, 2015) impact whether the salience of the formality level of variants plays a role in differing outcomes among variable structures.

In sum, by comparing the current study's results on future-time expression to those on negation and interrogatives, we were able to make a new observation about this group of 
NNSs' sociolinguistic competence: at least with regard to specific linguistic and sociostylistic constraints, they appeared to be less nativelike with future-time expression than the other variable structures under investigation. We believe that this observation is valuable, and we also hope to have shown that multiple, complementary analyses of the same dataset offer great potential for furthering knowledge about near-native sociolinguistic competence. While our preliminary reflection on the level of formality of variants is not a generalizable conclusion, it is a hypothesis that emerged from multifaceted analyses of a single dataset. Finally, we wish to stress that, although we have focused on formality, complementary analyses have the potential to be beneficial for furthering knowledge of other explanatory factors at play in the development of sociolinguistic competence.

\section{Conclusion}

The current study has provided new knowledge about sociolinguistic competence in additional language French by conducting a variationist analysis of the use of the IF, PF, and PI to express futurity in informal conversations between NNSs and NSs. The findings for the NNSs revealed both nativelike and non-native like patterns of use in terms of the frequency of occurrence of the forms and the constraints that condition their use. We also investigated a new sociostylistic factor in the investigation of future-time reference in French - topic seriousness - and found that it conditioned use for NNSs and NSs. Moreover, by comparing the current study's findings to those of other examinations of variation from the same dataset (Donaldson, 2016, 2017), we have offered important contributions to SLA. The present investigation, in conjunction with Donaldson (2016, 2017), serves as an example of research that has conducted multifaceted analyses of the same dataset and has shown that these types of analyses are important for further developing a comprehensive understanding of near-native sociolinguistic competence. We advocate, furthermore, that multiple, complementary analyses of a single participant group are essential for advancing the understanding of additional language acquisition more generally.

Correspondence should be addressed to Aarnes Gudmestad.

Email: agudmest@vt.edu

\section{Notes}

${ }^{1}$ We use this abbreviation to refer exclusively to near-native speakers, not non-native speakers more generally. We recognize that near-nativeness is complex and operationalize near-native in a way which is consistent with how other scholars have used this term (e.g., Bartning, Forsberg, \& Hancock, 2009; Birdsong, 1992; Birdsong \& Molis, 2001; Coppieters, 1987).

${ }^{2}$ We do not use the terms 'native-speaker norm/target' and 'NSs' to refer to a monolingual target. Instead, we use them generally to refer to individuals who have been exposed to the target language since birth and who have had varying degrees of exposure to additional languages. 
${ }^{3}$ Due to space constraints, see Geeslin \& Long (2014) for a discussion on the evaluation of linguistic variables and the difference between same-meaning and same-function variation (p. 31).

${ }^{4}$ In Gudmestad et al. (2018) we investigated 12 NSs of Hexagonal French, 10 of whom we examine in the current study. Since the focus of this previous investigation was on the role of the present indicative in future-time contexts, we do not discuss it here.

${ }^{5}$ Most of this research has adopted a sociolinguistic perspective (see Ayoun, 2014, and Moses, 2002, for exceptions). Although there is work on different data types, the results do not show a clear divergence by task type.

${ }^{6}$ The size of the participant pool prevents us from being able to investigate the role of intensity of contact with NSs (Blondeau et al., 2014). We leave this issue to future research.

${ }^{7}$ Since most of the participants are women, it may be that the current study's findings reflect women's speech. Whether there are gender differences for future-time reference and this population is left to future research.

${ }^{8}$ Given the homophony between the conditional and IF in the first-person singular and the fact that vous was very infrequent in the dataset, we did not include grammatical person in the analysis.

${ }^{9}$ Our operationalization of this factor diverges from Wagner and Sankoff (2011) because quand 'when' and si 'if' statements were so infrequent that we were not able to examine them as separate categories.

${ }^{10}$ See Gudmestad et al. (2018) for a discussion of this variable and an operationalization of LTI that goes beyond the clause level.

${ }^{11}$ Although some researchers have called this factor adverbial specification, we use the term LTI in order to make the distinction between morphological marking of futurity on verbs and other (mostly lexical) marking of futurity. LTI includes the latter only. Our use of LTI is also consistent with our previous work on this dataset (Edmonds et al., 2017 and Gudmestad et al., 2018).

${ }^{12} \mathrm{We}$ recognize that it has become increasingly common in applied linguistics to generate mixed-effects models with fixed effects and a random effect for participant. However, although it is possible to run mixed-effects models in $\mathrm{R}$, the dependent variable must be binary. At the time we analyzed the data, $\mathrm{R}$ did support mixed-effects models when the dependent variable is multinomial, which is the case in the current study. Nevertheless, we compared the results reported here to a set of Bonferroni-corrected binary regression models including participant as a random effect. These models revealed similar results to those found with the two multinomial models. 
${ }^{13}$ The NNSs used 34 certainty markers, 19 uncertainty markers, and 292 cases without an (un)certainty marker. The NSs produced 24 certainty markers, 11 uncertainty markers, and 273 contexts without an (un)certainty marker.

${ }^{14}$ See Mougeon et al. (2010), Howard (2012a), and Kanwit et al. (2015) for other research that has investigated multiple variable structures with the same participant pool.

\section{References}

Armstrong, N. R. (2001). Social and stylistic variation in spoken French: A comparative approach. Philadelphia/Amsterdam: John Benjamins. doi: 10.1075/impact.8

Armstrong, N. (2002). Variable deletion of French ne: A cross-stylistic perspective. Language Sciences, 24, 153-173. doi: 10.1016/s0388-0001(01)00015-8

Armstrong, N., \& Pooley, T. (2010). Social and linguistic change in European French. New York: Palgrave Macmillan. doi: 10.1057/9780230281714_1

Ayoun, D. (2014). The acquisition of future temporality by L2 French learners. Journal of French Language Studies, 24, 181-202. doi: 10.1017/s0959269513000185

Bartning, I., Forsberg, F., \& Hancock, V . (2009). Resources and obstacles in very advanced L2 French: Formulaic language, information structure and morphosyntax. Eurosla Yearbook, 9, 185-211. doi: doi.org/10.1075/eurosla.9.10bar

Billiez, J., \& Buson, L. (2013). Perspectives diglossique et variationnelle Complémentarité ou incompatibilité? Quelques éclairages sociolinguistiques. Journal of French Language Studies, 23(1), 135-149. doi:10.1017/ S0959269512000397

Birdsong, D. (1992). Ultimate attainment in second language acquisition. Language, 68, 706-755. doi: $10.2307 / 416851$

Birdsong, D., \& Molis, M. (2001). On the evidence for maturational constraints in second language acquisition. Journal of Memory and Language, 44, 235-249. doi: 10.1006/jmla.2000.2750

Blondeau, H., Dion, N., \& Ziliak Michel, Z. (2014). Future temporal reference in the bilingual repertoire of Anglo-Montrealers: A twin variable. International Journal of Bilingualism, 18(6), 674-692. doi: 10.1177/1367006912471090

Blondeau, H., \& Labeau, E. (2016). La référence temporelle au futur dans les bulletins météo en France et au Québec : regard variationniste sur l'oral préparé. Canadian Journal of Linguistics, 61(3), 240-258. doi: 10.1353/cj1.2016.0023

Comeau, P. D. (2011). A window on the past, a move toward the future: Sociolinguistic and formal perspectives on variation in Acadian French. Doctoral dissertation, York University.

Coppieters, R. (1987). Competence differences between native and near-native speakers. Language, 63, 544-573. doi: 10.2307/415005

Donaldson, B. (2016). Aspects of interrogative use in near-native French: Form, function, and register. Linguistic Approaches to Bilingualism, 6, 467-503. doi: 10.1075/lab.14024.don 
Donaldson, B. (2017). Negation in near-native French: Variation and sociolinguistic competence. Language Learning, 67, 141-170. doi: 10.1111/lang.12201

The Douglas Fir Group. (2016). A transdisciplinary framework for SLA in a multilingual word. The Modern Language Journal, 100(Supplement 2016), 19-47. doi: 10.1111/modl.12301

Edmonds, A., \& Gudmestad, A. (2015). What the present can tell us about the future: A variationist analysis of future-time expression in native and non-native French. Language, Interaction and Acquisition, 6(1), 15-41. doi:10.1075/lia.6.1.01edm

Edmonds, A., Gudmestad, A., \& Donaldson, B. (2017). A concept-oriented analysis of future-time reference in native and near-native Hexagonal French. Journal of French Language Studies, 27(3), 381-404. doi:10.1017/s0959269516000259

Ellis, N. C. (2012). Frequency-base accounts of second language acquisition. In S. M. Gass \& A. Mackey (Eds.), The Routledge handbook of second language acquisition (pp. 193-210). London: Routledge. doi: 10.4324/9780203808184.ch12

Fonseca-Greber, B. B. (2007). The emergence of emphatic 'ne' in conversational Swiss French. Journal of French Language Studies, 17, 249-275. doi: $10.1017 /$ s0959269507002992

Gass, S. M., Spinner, P., \& Behney, J. (Eds.) (2018). Salience in second language acquisition. London: Routledge. doi: 10.4324/9781315399027

Geeslin, K., \& Long, A. Y. (2014). Sociolinguistics and second language acquisition: Learning to use language in context. London: Routledge. doi: $10.4324 / 9780203117835$

Granger, S. (2009). The contribution of learner corpora to second language acquisition and foreign language teaching: A critical evaluation. In K. Aijmer (Ed.), Corpora and Language Teaching (pp. 13-32). Philadelphia/Amsterdam: John Benjamins. doi: 10.1075/scl.33.04gra

Gudmestad, A., \& Edmonds, A. (2015). Categorical and variable mood distinction in Hexagonal French: Factors characterising use for native and non-native speakers. Canadian Journal of Applied Linguistics, 18(1), 107-131.

Gudmestad, A., \& Edmonds, A. (2016). Variable future-time reference in French: A comparison of learners in a study-abroad and a foreign-language context. Canadian Journal of Linguistics, 61, 259-285. doi: 10.1353/cj1.2016.0024

Gudmestad, A., Edmonds, A., Donaldson, B., \& Carmichael, K. (2018). On the role of the present indicative in variable future-time reference in Hexagonal French. Canadian Journal of Linguistics, 63, 42-69. doi: 10.1017/cnj.2017.41

Hansen, A. B. (2016). French in Paris (Ile-de-France): A speaker from the 14th arrondissement. In S. Detey, J. Durand, B. Lake, \& C. Lyche (Eds.), Varieties of spoken French (pp. 123-136). New York: Oxford University Press. doi: 10.1093/acprof:oso/9780199573714.003.0009

Howard, M. (2012a). The advanced learner's sociolinguistic profile: On issues of individual differences, second language exposure conditions, and type of sociolinguistic variable. The Modern Language Journal, 96, 20-33. doi: 10.1111/j.1540-4781.2012.01293.x

Howard, M. (2012b). From tense and aspect to modality: The acquisition of future, conditional and subjunctive morphology in L2 French. A preliminary study. Cahiers Chronos, 24, 201-223. doi: 10.1163/9789401207188_011 
Kanwit, M., Geeslin, K. L., \& Fafulas, S. (2015). Study abroad and the SLA of variable structures: A look at the present perfect, the copula contrast, and the present progressive in Mexico and Spain. Probus, 27(2), 307-348. doi: 10.1515/probus2015-0004

Labov, W. (1972). Sociolinguistic patterns. Philadelphia: University of Pennsylvania Press. MacWhinney, B. (2000). The CHILDES Project: Tools for analyzing talk. Third Edition. Mahwah, NJ: Lawrence Erlbaum Associates.

Mitchell, R., Tracy-Ventura, N., \& McManus, K. (2017). Anglophone students abroad: Identity, social relationships, and language learning. London: Routledge. doi: $10.4324 / 9781315194851$

Moses, J. (2002). The development of future expression in English-speaking learners of French. Unpublished doctoral dissertation, Indiana University.

Mougeon, R., Nadasdi, T., \& Rehner, K. (2010). The sociolinguistic competence of French immersion students. Clevedon, UK: Multilingual Matters. doi: $10.21832 / 9781847692405$

Mougeon, F., \& Rehner, K. (2015). Engagement portraits and (socio)linguistic performance: A transversal and longitudinal study of advanced L2 learners. Studies in Second Language Acquisition, 37, 425-456. doi: 10.1017/s0272263114000369

Nadasdi, T., Mougeon, R., \& Rehner, K. (2003). Emploi du 'futur' dans le français parlé des élèves d'immersion française. Journal of French Language Studies, 13, 195219. doi: $10.1017 / \mathrm{s} 0959269503001108$

Poplack, S., \& Dion, N. (2009). Prescription vs. praxis: The evolution of future temporal reference in French. Language, 85, 557-587. doi: 10.1353/lan.0.0149

Poplack, S., \& St-Amand, A. (2007). A real-time window on 19th-century vernacular French: The Récits du français québécois d'autrefois. Language in Society, 36, 707-734. doi: 10.1017/s0047404507070662

Poplack, S., Lealess, A. and Dion, N. (2013). The evolving grammar of the French subjunctive. Probus, 25, 139-195. doi: 10.1515/probus-2013-000

Poplack, S., \& Turpin, D. (1999). Does the futur have a future in (Canadian) French? Probus, 11, 133-164. doi: 10.1515/prbs.1999.11.1.133

Preston, D. (2000). Three kinds of sociolinguistics and SLA: A psycholinguistic perspective. In B. Swierzbin, F. Morris, M. Anderson, C. Klee, \& E. Tarone (Eds.), Social and cognitive factors in second language acquisition: Selected proceedings of the 1999 Second Language Research Forum (pp. 3-30). Somerville, MA: Cascadilla.

Regan, V., Howard, M., \& Lemée, I. (2009). The acquisition of sociolinguistic competence in a study abroad context. Clevedon, UK: Multilingual Matters. doi: 10.1111/j.1467-9841.2010.00447_7.x

Richards, J. C., \& Schmidt, R. (2010). Longman dictionary of language teaching and applied linguistics. $4^{\text {th }}$ ed. Harlow, England: Longman. doi: $10.4324 / 9781315833835$

Roberts, N. S. (2012). Future temporal reference in Hexagonal French. University of Pennsylvania working papers in linguistics, 18, 97-106.

Roberts, N. S. (2016). The future of Martinique French: The role of random effects on the variable expression of futurity. Canadian Journal of Linguistics, 61(3), 286-313. doi: 10.1017/cnj.2016.29 
Sankoff, G., \& Vincent, D. (1977). L’emploi productif du ne dans le français parlé à Montréal. Le français moderne, 45, 243-254.

Sax, K. J. (2003). Acquisition of stylistic variation in American learners of French. Unpublished Ph.D. dissertation, Indiana University, Bloomington.

Tagliamonte, S. A. (2012). Variationist sociolinguistics: Change, observation, interpretation. New York: Wiley-Blackwell. doi: 10.1016/j.pragma.2012.04.006

Tarone, E. (2007). Sociolinguistic approaches to second language acquisition research 1997-2007. Modern Language Journal, 91, 837-848. doi: 10.1111/j.00267902.2007.00672.x

Tarone, E., \& Liu, G. Q. (1995). Situational context, variation and second-language acquisition theory. In G. Cook \& B. Seidlhofer (Eds.), Principles and practice in the study of language and learning: A Festschrift for H. G. Widdowson (pp. 107124). Oxford: Oxford University Press.

van Compernolle, R. A. (2015). Native and non-native perceptions of appropriateness in the French second-person pronoun system. Journal of French Language Studies, 25, 45-64. doi:10.1017/s0959269513000471

Villeneuve, A., \& Comeau, P. (2016). Breaking down temporal distance in a Continental French variety: Future temporal reference in Vimeu. Canadian Journal of Linguistics, 61(3), 314-336. doi: 10.1017/cnj.2016.30

Wagner, S. E., \& Sankoff, G. (2011). Age-grading in the Montreal French inflected future. Language Variation and Change, 23, 275-131. doi: 10.1017/s0954394511000111 


\section{Appendix}

Table A1

Distribution of verb forms according to temporal distance for NNSs

\begin{tabular}{lccccccc}
\hline \multirow{2}{*}{ Temporal distance } & \multicolumn{2}{c}{ IF } & \multicolumn{2}{c}{ PF } & PI & Total \\
\hline Today & $\#$ & $\%$ & $\#$ & $\%$ & $\#$ & $\%$ & 45 \\
Less than a week & 0 & 0 & 34 & 75.6 & 11 & 24.4 & 58 \\
Less than a month & 5 & 8.6 & 23 & 39.7 & 30 & 51.7 & 38 \\
Greater than a month & 4 & 10.5 & 11 & 28.9 & 23 & 60.5 & 65 \\
Ambiguous & 13 & 20.0 & 33 & 50.8 & 19 & 29.2 & 139 \\
\hline
\end{tabular}

Table A2

Distribution of verb forms according polarity for NNSs

\begin{tabular}{lcrrrrrr}
\hline \multirow{2}{*}{ Polarity } & \multicolumn{1}{c}{ IF } & \multicolumn{3}{c}{ PF } & PI & \multirow{2}{*}{ Total } \\
\hline Negative & 6 & 19.4 & 20 & 64.5 & 5 & 16.1 & 31 \\
Positive & 44 & 14.0 & 180 & 57.3 & 90 & 28.7 & 314 \\
\hline
\end{tabular}

